\title{
Screening for psychiatric morbidity in police custody: results from the HELP-PC project
}

\author{
lain McKinnon, ${ }^{1}$ Samir Srivastava, ${ }^{2}$ Gurpreet Kaler, $^{3}$ Don Grubin ${ }^{1}$
}

The Psychiatrist (2013), 37, 389-394, doi: 10.1192/pb.bp.112.041608

${ }^{1}$ Newcastle University and Northumberland, Tyne and Wear NHS Foundation Trust; ${ }^{2}$ School of Psychiatry, Northern Deanery; ${ }^{3}$ Northumberland, Tyne and Wear NHS Foundation Trust

Correspondence to lain McKinnon (iain.mckinnon@ncl.ac.uk)

First received 1 Oct 2012, final revision 31 May 2013, accepted 26 Jun 2013

\begin{abstract}
Aims and method To ascertain the efficacy of custody health screening for mental disorders. We assessed a sample of detainees for the presence of mental disorders and the need for an appropriate adult. The assessments were carried out using pragmatic interviews and examinations supported by structured tools. Where possible, we attributed a probable clinical diagnosis based on the information available to us. The need for an appropriate adult was judged based on this information and capacity assessments.
\end{abstract}

Results Existing screening procedures missed a quarter of cases of severe mental illness and moderate depression; they also failed to detect about a half of those at risk of alcohol withdrawal and $70 \%$ of those at risk of withdrawal from crack cocaine. The need for an appropriate adult was not recognised in more than half of cases.

Clinical implications Consideration should be given to modifying police screening procedures for mental and associated disorders so that detainees receive the appropriate attention.

Declaration of interest None.
High levels of psychiatric morbidity, ${ }^{1-5}$ drug and alcohol dependence $^{6-8}$ and rates of suicidal ideation ${ }^{9}$ are found in prison inmates. Less research has been carried out in police custody. An observational study in London in the 1990s estimated the prevalence of serious mental disorder to be $2 \% .{ }^{10}$ More recent investigations have reported $16 \%$ with histories of self-harm and $7 \%$ who had been detained under the Mental Health Act $1983 .{ }^{11}$ There is also evidence linking the use of drugs and alcohol to the presentation of mental disturbance in custody, ${ }^{12}$ along with the contribution of these factors to deaths in custody. ${ }^{13,14}$ In a previous evaluation of consecutive custody records in London, we found evidence of mental disturbance in a third and psychosis in approximately $3 \%$ of detainees. ${ }^{15}$ These prevalences are rather lower than those reported in prisons ${ }^{5}$ and are not dissimilar to those described in general practice. ${ }^{16}$

Statutory responsibility for the welfare of detainees in police custody in England and Wales rests with the custody sergeant. ${ }^{17}$ The sergeant must decide whether to refer a detainee to a healthcare professional. In addition, in the case of 'mentally vulnerable detainees' (a term employed within the Police and Criminal Evidence Act 1984), the sergeant should consider calling for an appropriate adult. ${ }^{17}$ Sergeants are not clinically trained; in the London Metropolitan Police Service, new sergeants receive brief training on the identification of medical conditions requiring further assessment or treatment, but there is no ongoing training.

We have recently published data from the Health Screening in Police Custody (HELP-PC) project, demonstrating that current health screening procedures in London custody suites miss substantial amounts of general health morbidity. ${ }^{18}$ In the current paper we concentrate on the psychiatric morbidity we observed in police custody detainees, the efficacy of police health screening procedures in identifying 'at-risk' individuals, and discuss the implications for managing detainees with mental disorder.

\section{Method}

The HELP-PC project is an evaluation of health screening procedures for custody detainees aged 18 and over in London, UK. It was carried out in two police stations. The method is described in detail in our previous paper. ${ }^{18}$

In summary, the aim of the project is to obtain prevalence data from an unselected cohort of police custody detainees, and to judge the efficacy of the police health screen by comparing it with a clinical research interview by a psychiatrist. Full clinical assessment was limited to a maximum of $30 \mathrm{~min}$ because of the logistics of busy custody suites. Due to this limited time window the assessment of mental disorder employed a synthesis of symptom checklists adapted from ICD-10, ${ }^{19}$ the 18-item Brief Psychiatric Rating Scale (BPRS-18) ${ }^{20}$ and clinical judgement.

With regard to mentally vulnerable detainees who required an appropriate adult, we concentrated on detainees with suspected serious mental illness, intellectual disability and other cognitive problems judged not to be related primarily to the reversible effects of drugs or alcohol. The presence of any of these vulnerability factors was 
considered to require the presence of an appropriate adult during police interview of the detainee.

In total, 630 individuals were eligible for inclusion in the study, described in the flowchart in Fig. 1. Interviews with 237 individuals took place between April 2009 and September 2010. A further 11 who lacked capacity to consent to the formal interview as a result of mental disturbance were also included in the analysis. For the purposes of the evaluation of mental disturbance therefore, data from 248 detainees were available, representing a third of those who were eligible - others declined to take part, were unavailable or were deemed too violent for interview. The characteristics of the sample are described in Table 1.

Results relating to physical morbidity and injuries are described elsewhere. ${ }^{18}$ Mental vulnerability as a result of intellectual disability, although referred to later, will be described in more detail elsewhere. Here we present results relating to psychiatric disturbance, suicide risk and morbidity related to the misuse of substances.

\section{Ethical approval}

Ethical approval was obtained from Newcastle and North Tyneside Research Ethics Committee in 2008 (08/H0906/ 130).

\section{Results}

\section{Mental disorders}

Based on clinical evaluation and capacity assessment, 96 detainees (39\%) were assessed as presenting with some form of mental disorder (Fig. 2). The police screen detected a mental disturbance in $\mathbf{5 0}$ of the clinically recognised cases (52\%, 95\% CI 42-62).
Table 1 Characteristics of detainees who consented to take part in the clinical research interview $(n=237)$

Characteristic

\begin{tabular}{lc}
\hline Age, years: mean (median) & $33.3(32)$ \\
\hline Male, $n(\%)$ & $197(83)$ \\
\hline Ethnicity, $n(\%)$ & $29(12)$ \\
Black and minority ethnic British & $94(40)$ \\
White British & $68(29)$ \\
Black and minority ethnic non-British & $42(18)$ \\
White non-British & $132(56)$ \\
\hline Unemployed, $n(\%)$ &
\end{tabular}

Eight detainees reported prior admission to psychiatric hospital, of whom five had been detained under the Mental Health Act.

\section{Psychosis and non-psychotic affective disturbances}

The number of detainees judged to have these mental disorders and the performance of the police screen in their detection is presented in Table 2.

No detainees in our sample satisfied ICD-10 criteria for severe depressive disorder. ${ }^{19}$

Of the 19 detainees with psychosis, 14 completed the BPRS-18. Those with psychosis had significantly higher BPRS scores than the non-psychotic group $\left(\chi^{2}\right.$-test for trend (d.f.=1) 25.341, $P=0.000$ ). Subscales for disorganisation, mannerisms, suspiciousness, unusual thought content and blunted affect were scored higher for the psychosis group (all $P<0.001$ ). The subscale for hallucinatory behaviour was

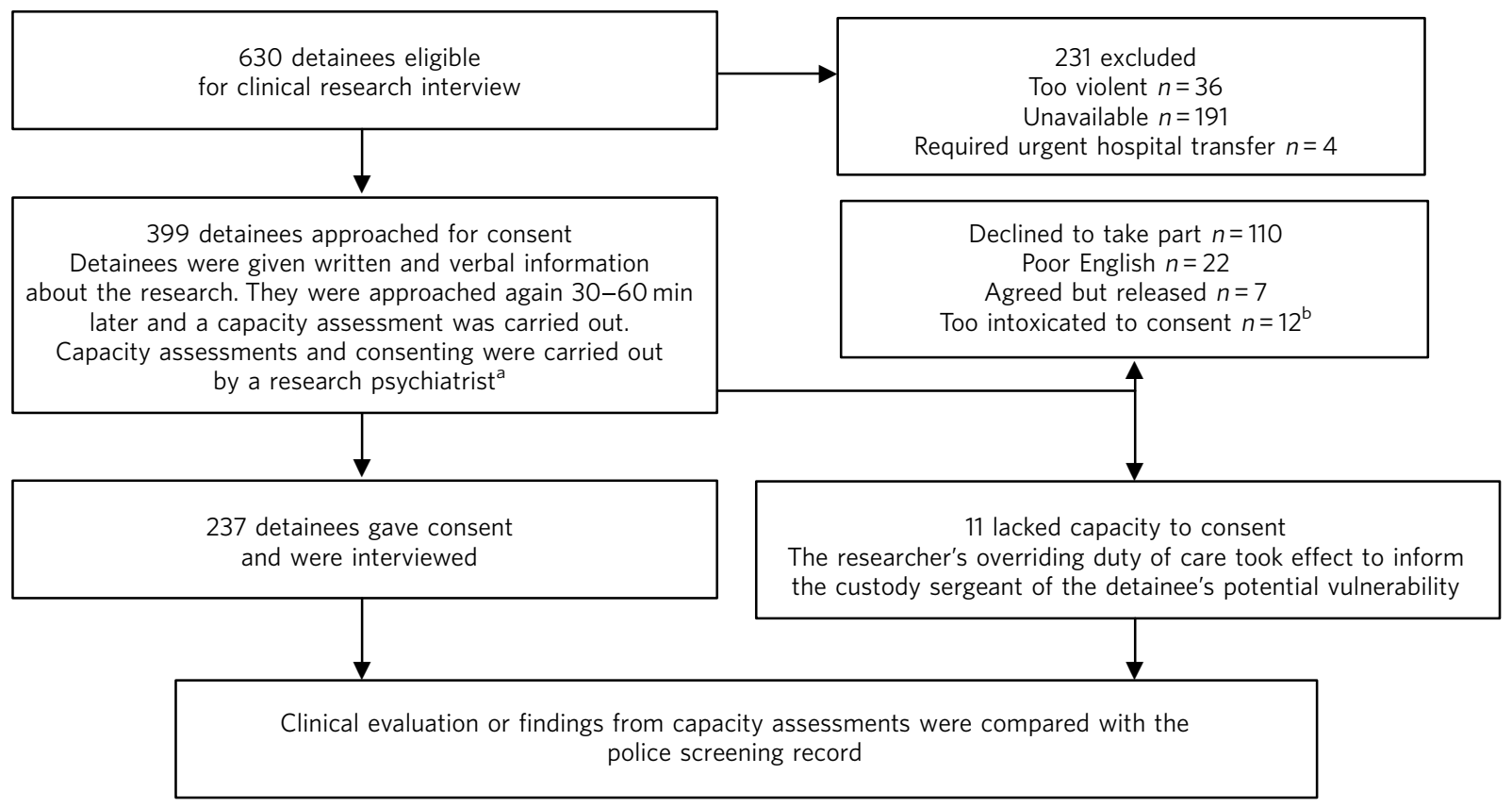

Fig 1 Flowchart describing the recruitment of eligible detainees.

a. Given the short amount of time for detainees to consider taking part, arrangements were made for retrospective withdrawal.

b. Intoxicated detainees were approached again to see whether they had sobered. This number refers to those who had not sobered sufficiently for consent to be obtained. 


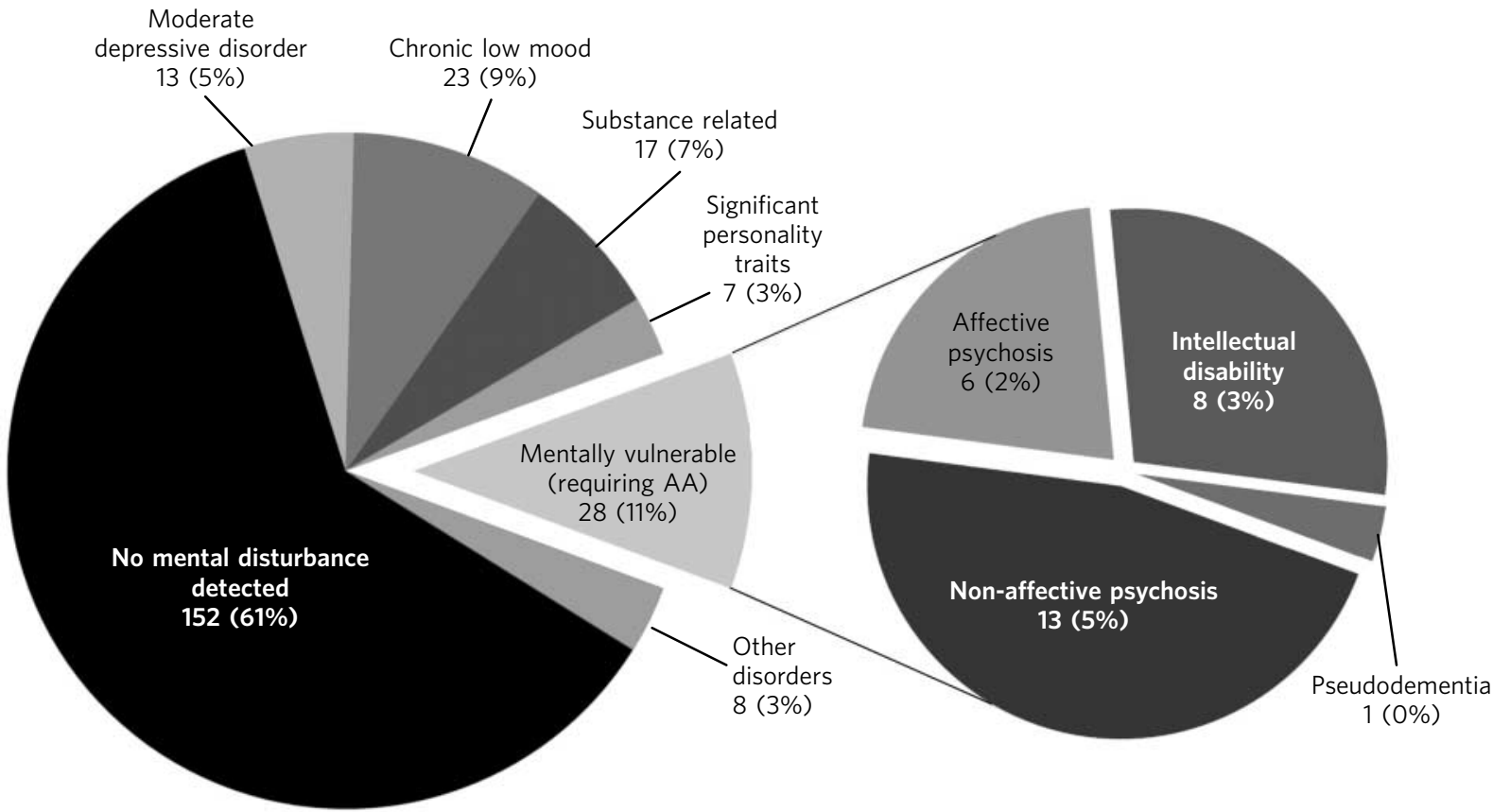

Fig 2 Mental status ascribed to 248 custody detainees. AA, appropriate adult.

also scored higher $\left(\chi^{2}\right.$-test for trend (d.f. $\left.=1\right) 4.279$ $(P<0.05)$. Detection rates of detainees with a mental disturbance related primarily to the effects of substances are presented in Table 3.

We have previously reported the efficacy of the police screen in the detection of detainees who are current class A substance users and those at risk of alcohol withdrawal. ${ }^{18}$ In summary, the majority of those at risk of alcohol withdrawal and those who had used crack cocaine prior to arrest were missed; those at risk of opiate withdrawal fared better.

\section{Other disorders}

In the time available it was not possible to ascribe personality disorder diagnoses to detainees. However, from the clinical history we judged that the effect of significant personality factors was a primary issue in seven individuals. Two of these detainees displayed behaviour disturbances so significant that they lacked capacity to consent to take part in the study, although there was no evidence of cognitive impairment. A mental disturbance was detected by the police screen in four of the seven cases, and although none were referred for an appropriate adult, all but one was referred to the healthcare professional.

\section{False positives}

The police screen identified mental disturbance in 59 of the 248 detainees from our sample; we found no evidence of mental disorder in 9 of these individuals (15\%, 95\% CI 7-27).

\section{Suicidal ideation}

In our recent paper, ${ }^{18}$ we reported that the police screen detected between a third and a half of detainees who had previously attempted suicide or who had active suicidal

\begin{tabular}{|c|c|c|c|c|c|c|c|}
\hline Diagnosis & $\begin{array}{l}\text { Number } \\
\text { identified } \\
\text { by clinical } \\
\text { research } \\
\text { evaluation }\end{array}$ & $\begin{array}{c}\text { Mental } \\
\text { disturbance } \\
\text { detected by } \\
\text { police } \\
\text { screen, } n\end{array}$ & $\begin{array}{l}\text { Proportion, \% } \\
(95 \% \mathrm{Cl})\end{array}$ & $\begin{array}{c}\text { Number } \\
\text { referred for } \\
\text { assessment by } \\
\text { healthcare } \\
\text { professional }^{a}\end{array}$ & $\begin{array}{l}\text { Proportion, \% } \\
(95 \% \mathrm{Cl})\end{array}$ & $\begin{array}{l}\text { Appropriate } \\
\text { adult } \\
\text { called, } n\end{array}$ & $\begin{array}{l}\text { Proportion, \% } \\
(95 \% \mathrm{Cl})\end{array}$ \\
\hline Psychosis & 19 & 15 & 79 (54-94) & 18 & 95 (74-99) & 8 & $42(20-67)$ \\
\hline Moderate depressive disorder & 13 & 9 & $69(39-91)$ & 6 & $46(19-75)$ & 0 & N/A \\
\hline Mild depressive disorder & 23 & 11 & $48(29-69)$ & 14 & $61(39-80)$ & 1 & $4(0-22)$ \\
\hline $\begin{array}{l}\text { Intoxicating effects of } \\
\text { substances as primary cause } \\
\text { of mental disturbance }\end{array}$ & 17 & 5 & $24(7-50)$ & 13 & $76(50-93)$ & 2 & $12(1-36)$ \\
\hline $\begin{array}{l}\text { Personality factors as } \\
\text { primary cause of mental } \\
\text { disturbance }\end{array}$ & 7 & 4 & $57(18-90)$ & 1 & $14(0-58)$ & 0 & N/A \\
\hline
\end{tabular}

$\mathrm{N} / \mathrm{A}$, not applicable.

a. The reason for referral did not necessarily relate to the mental disturbance. 
Table 3 Referrals made by the police sergeants following screening for 19 detainees with psychosis

\begin{tabular}{lccc}
$n(\%)$ & $\begin{array}{c}\text { No action } \\
\text { taken, } n\end{array}$ & $\begin{array}{c}\text { Sergeant called healthcare } \\
\text { professional and } \\
\text { appropriate adult, }{ }^{a} n\end{array}$ \\
\hline Mental disturbance detected by sergeant & $15(79)$ & 1 & 8 \\
\hline Mental disturbance not detected by sergeant & $4(21)$ & 0 & 0 \\
\hline
\end{tabular}

a. No cases had an appropriate adult called and no healthcare professional referral.

b. An appropriate adult was subsequently recommended by the healthcare professional for six of these ten detainees.

ideation. From our current sample, 25 detainees disclosed current suicidal ideation on the Beck Scale for Suicide Ideation. ${ }^{21}$ Of these, $12(48 \%, 95 \%$ CI $28-69)$ had any risk of suicide documented on the police screen; 6 of these referred to current risk. Of 44 detainees who disclosed a prior suicide attempt, 15 (34\%, 95\% CI 20-50) had risk of suicide noted.

\section{Mental vulnerability}

Of the 28 detainees who were considered mentally vulnerable by the researcher and requiring an appropriate adult, 19 were assessed as being likely to have a psychotic disorder, 8 had clinical evidence of intellectual disability, and 1 had reported memory loss associated with an affective disturbance. An appropriate adult was called for 12 detainees in this group (43\%, 95\% CI 24-63).

\section{Discussion}

The HELP-PC project is a descriptive study of health morbidity and the efficacy of police health screening procedures within custody suites in London, UK. We considered, as far as possible, an unselected, consecutive sample of detainees. The sensitivity and specificity of the police screen was evaluated over a range of morbidities. As far as we are aware, this is the first study to use this method and procedure in this setting. Previous studies carried out among police custody detainees have relied on observational data ${ }^{10}$ or pre-selected subgroups. ${ }^{11,22,23}$

This paper considers the ability of standard police screening procedures to identify detainees with mental disorders. Although a mental disturbance was detected in $79 \%$ of cases of detainees with serious mental illness, an appropriate adult was called in only $42 \%$ of these cases. Although $95 \%$ of the detainees with psychosis were referred to the healthcare professional, examination of the custody records indicated that the reason for referral was not consistently documented. Moreover, even though two-thirds of detainees with moderate depressive disorder were described on the screen as having a mental disturbance, fewer than half were referred to the healthcare professional for further assessment.

With respect to the identification of detainees with significant mental health needs, our data suggest that the sensitivity of the screen can be improved. One approach may be to use evidence-based questions and observational cues within a screening package. A number of factors from the BPRS showed discriminatory potential in the identification of detainees with serious mental illness.
However, this is not the only consideration. As a series of undirected questions, the current screen lacks the scope to differentiate between categories of mental disorders. Even where a mental disturbance is acknowledged, the screen provides little assistance to the custody officer on what course of action to take. This appears to be reflected in the low rates of calls for appropriate adults, along with evidence that the referrals to the healthcare professional lack focus on the mental disorder.

Both a lack of and delays in obtaining appropriate adults have previously been identified as significant problems. $^{24}$ It is unclear how much this influences sergeants' decisions not to call for an appropriate adult where a mentally vulnerable detainee is identified. The absence of a specific definition for mental vulnerability under the Police and Criminal Evidence Act serves to compound this issue. ${ }^{17}$

Only a third of detainees with a risk history of selfharm or who expressed current suicidal ideation were screened positive for risk of suicide. Sergeants have detainees' self-reports, the police national computer and prior custody records at their disposal. Again, however, suicide risk and information from other sources were not systematically or consistently recorded. Furthermore, this part of the screen does not direct the sergeant to acknowledge mental disturbance detected elsewhere. Screening takes place at the custody desk: a busy, noisy environment, far from ideal for this type of enquiry. Although it is unlikely to be feasible to alter the circumstances in which this questioning takes place, there is scope to improve the documentation and communication of these risks among custody staff.

The low detection rate of detainees at risk of withdrawal from crack cocaine reflects our previous findings. ${ }^{15}$ The custody suites where this study took place were drug-testing sites within the Metropolitan Police Service; we expected that a higher proportion of detainees would have divulged this information in the knowledge they were likely to be tested for drugs. At reception into custody, a detainee's fear of harming their defence by divulging class A drug use may outweigh their concern about drug withdrawal hours later while still in custody. Drug withdrawal during police interview may have detrimental effects on a detainee's ability to concentrate and give reliable evidence. $^{25}$ It is unclear how changes to self-report screening for crack cocaine would benefit detection rates.

\section{Limitations}

We could only interview $38 \%$ of the available detainees, giving rise to the possibility of selection bias. Those 
with problems requiring the attention of a healthcare professional stayed in custody longer, and were thus more likely to be approached and have their consent obtained by researchers. It is not possible to say whether the group we missed had differing levels of morbidity than those we interviewed or whether psychiatric morbidly was missed by the police screen in these cases.

Relying on self-report as a key part of the method can lead to reporting bias in detecting psychiatric morbidity. However, obtaining detainees' general practice or psychiatric records was not feasible.

The window of opportunity for recruiting and carrying out clinical evaluations of detainees while in custody is narrow: at most $30 \mathrm{~min}$. We opted for a pragmatic, structured clinical history carried out by post-membership research psychiatrists. This has the drawback of lacking the robustness of validated tools and meant that we were not in a position to make judgements about the cause of psychosis where there was comorbid substance use. Despite the limitations of this approach in terms of diagnostic validity, it reflects the pragmatic approach that would be employed by a psychiatrist 'on call' attending a custody suite to give an opinion on mental disorder.

\section{Implications for clinical practice}

That the screen performed poorly in respect of detection and documentation of certain areas of psychiatric and associated morbidity is of considerable concern given the evidence linking psychiatric and drug-related mental disturbance to deaths in custody. ${ }^{14,26}$

Other significant developments are changes to the provision of liaison and diversion services in police custody. Recent reports have highlighted the need to identify detainees at the earliest stages within the criminal justice system. ${ }^{27,28}$ Dedicated liaison and diversion services are now emerging; it is conceivable that the role of screening for mental disorders may be assumed by these teams. However, the Police and Criminal Evidence Act requires the custody sergeant to assume overall responsibility for the detainee while in custody. Furthermore, there are other significant morbidities to consider, including physical health, injuries and risk of alcohol withdrawal, for which more robust screening is required as we have previously reported. ${ }^{18}$ Taken together, there is still a need to improve overall screening procedures for detainees at reception by custody sergeants. Potential benefits include:

- improved identification and documentation of morbidity

- providing a well-defined pathway for detainees with health problems

- enhancing the police's interactions with health services by way of more relevant clinical information being available

- improved safety of detainees within the custody suite by more effective highlighting of risks

- improved inter-agency communication of health and associated risk (e.g. courts, probation, prison services).

It should be acknowledged that custody sergeants are a heterogeneous group, with a wide range of experience. Some will have more proficiency in identifying detainees with mental disorder than others. Throughout the duration of this study, researchers observed that some sergeants would expand on screening questions to acquire a more detailed profile of a detainee; others tended to stick more rigidly to the questions on the screen. Researchers also observed that there was a wide range of opinions on how to effectively manage detainees with mental disorder.

As part of the wider reforms, the Metropolitan Police Service is beginning to introduce civilian staff to undertake activities on behalf of the custody officer; these include recording the health screening of custody detainees, under the supervision of a custody officer. Although these staff members receive training on the role of booking detainees into custody, many lack the hands-on experience of a police sergeant, which may further exacerbate the issue of missing significant cases. Therefore a more structured approach to identification along with observational cues may be of benefit.

Given these considerations, we recommend that modifications be made to police screening procedures to improve their efficacy, provide a method of documenting significant findings, and signpost appropriate pathways for detainees who screen positive. Care must be taken, however, not to avoid having an adverse effect on specificity leading to more false positive results; this could have significant resource implications for health cover within the custody suite. Additionally, given the time constraints in a busy custody suite, it will be important not to increase the time needed to carry out the health screen, particularly if any improvement is likely to be marginal. This process should be structured, based on the currently available evidence, and piloted with a robust evaluation of efficacy and impact on health and service outcomes. To evaluate the efficacy of such modifications, a pilot of a modified health screen is underway within the Metropolitan Police Service.

\section{Funding}

This phase of the HELP-PC project was supported by a small grant from Northumberland, Tyne and Wear NHS Foundation Trust.

\section{Acknowledgements}

We wish to thank Sergeant Cathy Nicholson from the Metropolitan Police Service Custody Directorate who provided essential support to the research team during the data collection. Further thanks to Mr Graham Manfield, Superintendent Dave Imroth and Sergeant Alistair Morley for their support. Inspector John Phillips (Wimbledon Custody), Inspector Tony Rayner and Sergeant Michael Clayman (both Islington Custody) provided on-site assistance at their respective custody suites.

Dr Margaret Stark, Forensic Physician and formerly Medical Director of the Metropolitan Police Service, provided further medical advice to I.M and D.G., orienting them to Police Medical Services in London. Dr Julie Thorp spent time assisting I.M. with data collection and preparation.

\section{About the authors}

lain McKinnon is an NIHR Doctoral Research Fellow, Newcastle University, and an Honorary Clinical Fellow in Forensic Learning Disability Psychiatry, Specialist Services, Northumberland, Tyne and Wear NHS Foundation Trust. Samir Srivastava is a Specialty Registrar in Forensic Psychiatry, School of Psychiatry, Northern Deanery. Gurpreet Kaler is Specialty Doctor in Forensic Psychiatry, Specialist Services, Northumberland, Tyne and Wear NHS Foundation Trust. Don Grubin is a Professor of Forensic Psychiatry, 
Institute of Neuroscience, Newcastle University, and an Honorary Consultant Forensic Psychiatrist, Specialist Services, Northumberland, Tyne and Wear NHS Foundation Trust.

\section{References}

1 Teplin LA. Psychiatric and substance abuse disorders among male urban jail detainees. Am J Public Health 1994; 84: 290-3.

2 Brooke D, Taylor C, Gunn J, Maden A. Point prevalence of mental disorder in unconvicted male prisoners in England and Wales. BMJ 1996; 313: 1524-7.

3 Birmingham L, Mason D, Grubin D. Prevalence of mental disorder in remand prisoners: consecutive case study. BMJ 1996; 313: 1521-4.

4 Powell TA, Holt JC, Fondacaro KM. The prevalence of mental illness among inmates in a rural state. Law Hum Behav 1997; 21: 427-38.

5 Singleton N, Melzer H, Gatward R, Coid J, Deasey D. Survey of Psychiatric Morbidity Among Prisoners in England and Wales. Office for National Statistics, 1998.

6 Mason D, Birmingham L, Grubin D. Substance use in remand prisoners: a consecutive case study. BMJ 1997; 315: 18-21.

7 Peters RH, Greenbaum PE, Edens JF, Carter CR, Ortiz MM. Prevalence of DSM-IV substance abuse and dependence disorders among prison inmates. Am J Drug Alcohol Abuse 1998; 24: 573-87.

8 Brooke D, Taylor C, Gunn J, Maden A. Substance misuse as a marker of vulnerability among male prisoners on remand. Br J Psychiatry 2000 177: $248-51$

9 Borrill J, Burnett R, Atkins R, Miller S, Briggs D, Weaver T, et al. Patterns of self-harm and attempted suicide among white and black/mixed race female prisoners. Crim Behav Ment Health 2003; 13: 229-40.

10 Robertson G, Pearson R, Gibb R. The entry of mentally disordered people to the criminal justice system. Br J Psychiatry 1996; 169: 172-80.

11 Payne-James JJ, Green PG, Green N, McLachlan GM, Munro MH, Moore TC. Healthcare issues of detainees in police custody in London, UK. J Forensic Leg Med 2010; 17: 11-7.

12 Payne-James JJ, Wall IJ, Bailey C. Patterns of illicit drug use of prisoners in police custody in London, UK. J Clin Forensic Med 2005; 12: 196-8.

13 Leigh A, Johnson G, Ingram A. Deaths in Police Custody: Learning the Lessons. National Policing Improvement Agency, 1998.
14 Independent Police Complaints Commission. Deaths In or Following Police Custody: An Examination of the Cases 1998/9-2008/9. Independent Police Complaints Commission, 2010.

15 McKinnon I, Grubin D. Health screening in police custody. J Forensic Leg Med 2010; 17: 209-12.

16 Singleton N, Bumpstead R, O'Brien M, Lee A, Melzer H. Psychiatric Morbidity Among Adults Living in Private Households, 2000. Office for National Statistics, 2001

17 Home Office. Police and Criminal Evidence Act Code C. Home Office, 2008.

18 McKinnon IG, Grubin D. Health screening of people in police custody evaluation of current police screening procedures in London, UK. Eur J Public Health 2013; 23: 399-405.

19 World Health Organization. The ICD-10 Classification of Mental and Behavioural Disorders. WHO, 1992.

20 Hafkenscheid A. Psychometric evaluation of a standardized and expanded Brief Psychiatric Rating Scale. Acta Psychiatr Scand 1991; 84: 294-300.

21 Beck AT, Steer RA. Beck Scale for Suicide Ideation: Manual. Pearson, 1993.

22 Shaw J, Creed F, Price J, Huxley P, Tomenson B. Prevalence and detection of serious psychiatric disorder in defendants attending court. Lancet 1999; 353: 1053-6.

23 Scott D, McGilloway S, Donnelly M. The mental health needs of people with a learning disability detained in police custody. Med Sci Law 2006; 46: $111-4$

24 Nemitz T, Bean P. Protecting the rights of the mentally disordered in police stations: the use of the appropriate adult in England and Wales. Int J Law Psychiatry 2001; 24: 595-605.

25 Sigurdsson JF, Gudjonsson GH. Alcohol and drug intoxication during police interrogation and the reasons why suspects confess to the police. Addiction 1994; 89: 985-97.

26 Best D, Havis S, Strathdee G, Keaney F, Manning V, Strang J. Drug deaths in police custody: is dual diagnosis a significant factor? J Clin Forensic Med 2004 11: 173-82.

27 The Rt Hon. Lord Bradley. The Bradley Report: Lord Bradley's Review of People with Mental Health Problems or Learning Disabilities in the Criminal Justice System. Department of Health, 2009.

28 Lord Victor Adebowale. Independent Commission on Mental Health and Policing. House of Lords, 2013. 